\title{
Service Design Indicator Construction for Rehabilitation Needs of Institutional Long-Term Care for the Elderly
}

\author{
Wan-li WEI ${ }^{1,{ }^{*}}$, Shu-feng TSAI ${ }^{2}$, Ya-fen TSAI ${ }^{3}$ and Ya-Ling LO ${ }^{4}$ \\ ${ }^{1,3}$ Ming Chuan University, 5 De Ming Rd., Gui Shan District, Taoyuan City 333, Taiwan \\ ${ }^{2}$ Mackay Medical College, 46 Sec. 3, Zhongzheng Rd., Sanzhi Dist., New Taipei City \\ 252, Taiwan
}

*Corresponding author. E-mail: wanliwei@mail.mcu.edu.tw

Keywords: Long-term care, Service design, Rehabilitation needs, Service design indicator.

\begin{abstract}
Taiwan was officially an aging society since 1993. Therefore, there are more and more long-term care requirements from people because of the increasingly aging population. Rehabilitation Needs is also one of the long-term care services, and this study is aimed for Service design indicator (SDI) construction for Rehabilitation Needs of long-term care system in order to not only fulfill Long-Term Care Stakeholders' Needs (LTCNs) but also consider customer emotional experiences of Long-Term Care Direct Stakeholders (LTCDS) for better caring quality offering and customer experiences creating for Long-Term Care User (LTCU). The first stage of this study is literature review as the basis for research surveys, identify service design point of view to work out product design aspects onto service design viewpoints by three major aspects: 1. the rehabilitation needs of LTCU; 2. the customer emotional experiences aspects such as service experiences, product experiences, activity experiences and space experiences; 3 . LTCS. The second stage of this study follows four principles of service design: user-centered design, co-creative, continuous improvement and touchpoints evidencing. The base of this research is institutional long-term care system, and the needs and desires of LTCS are obtained by in-depth interview and observation. The final stage of this study is to construct SDI for rehabilitation needs to meet LTCSNs.
\end{abstract}

\section{Introduction}

Taiwan's elderly population has amounted to $7 \%$ in 1993, that is, Taiwan has officially entered the aging society since 1993, and over $10 \%$ in 2007 . It is estimated to reach $14 \%$ and becomes an aging society in 2018, and will reach $20 \%$ become the s hyper-aged society, that is, about one in every five people is elder persons who over 65 years old [1]. The increase of elderly population is associated with the necessity of supporting measures of health, environment, health care system and completed social welfare. It is necessary to respond to this phenomenon, the Executive Yuan established promote a team of long-term care project group in 1999, promoting long-term care plans. In order to guarantee the right of long-term care user, the Legislative Yuan has adopted of the draft of "Long-term care service method" on February 23th, 2012, furthermore, elder population has increased year by year in Taiwan, follow close on the problem of care needs is heavily growing, however, in our country, currently hasn't any design's oriented aim on LCSNs [2]. Pay great attention to emotional experience of customers during using process and becomes a systematization competitive strategy, rules and process operation mechanism. 
Therefore, this research aims to build the SDI of long term care rehabilitation needs, through in-depth interviews gather life in institutional long-term care service system of LTCS, to seek consistency of SDI. This research focuses on long term care institutional services as the main object, select conservation organization for the elderly, maintenance institutions and Nursing Care Center of disabled persons, design questionnaires for different long-term care direct stakeholders and process interview, also, looking for physical treatment therapist and functions treatment therapist as interviewer, through their experience, understanding the mainly current situation of rehabilitation process in institutional long-term care service system to find contact points, and pain points and opportunities, followed service design principles, and the three mainly measure dimensions, the basic living needs of LTCU, emotional experience and long-term care direct stakeholders, to design the questionnaire. According to measure dimensions to identify SDI, and develop service design indicator of rehabilitation needs for long-term care service institution residents, as a basis for new product design and existing services process.

\section{Literature Review}

\section{Service Design}

Service design is one innovation focus on user (user-centered innovation) which is different from focused on entity products and digital interface design, its design is about the process of provides innovation service, to improve continuously, practice more systematic which close to user's needs of innovation kinetic energy. Customer in process of consumption is no longer just pay attention on products basic of function and benefits, but on customers' imagine creative experience and consumption situation. Therefore, service design is also one kind of design concept for service innovation. It also aims at products, events, services, or space to link customers' experience, and through systems and processes, strategies, language, policy or ideology overall considerations. To create a cross-field structure profession platform which is suitable for user experience service form $[3,4]$.

For designer, service design aim to customer's experience and value of co-design and co-creation, with designer's sense degrees combines elements and tool of cross-field, to reached five a target: 1 . to meet customer satisfaction and experience; 2 . designer self-satisfaction and achievements; 3. solution problem; 4. beauty and quality performance; 5. continuous development of environment and economic. Saco and Goncalves believe that service design is the way of solving the problem, and extend peoples' feelings by technology, then through the emotion and experience, creating suitable design and engineering-oriented view [5]. European service design expert Birgit Mager also said that: for enterprise or organization, service design is a planning activity. First, established up internal service program, then based on user viewpoints to create useful, usable and desirable, "customer emotional experience", and then bring profit to enterprise and forms of differences of service providing. In addition, when communicating with corporate executives, the main purpose is to let manager open mind, with wider horizons to understand universal service designs can lead business to success, namely service design and customer experience are interrelated. In some specific situation, when enterprises contact with customer need to focus on how to satisfy with customers' expectations [6]. 


\section{Long-Term Care}

It's so-called long-term care, refers to the physical and mental disability (long-term care patients), those who need to be provided a set which includes medical care, nursing care, personal care, and social support in a long time. The purpose is for promoting or keeping physical functions, improving independent normal living functions [7]. Lin further pointed out that long-term care is for people who are nature or nurture lost their normal living function, provides long-term of health care, personal care and social service [8]. Long-term care needs assessment, usually is Barthel Index, which called "ADLs" as well, that is, daily activities (activities of daily living, ADLs), such as eating, dressing, moving, using the toilet, walking, putting on underwear, socks and other items, as well as the IADL scale, that is, instrumental activities of daily living (IADLs), such as shopping, outdoor activities, cooking, household keeping, washing clothes and other items and the degree of mental function as the basis of assessment.

\section{ERG Theory and Rehabilitation Needs}

Maslow put humans needs into order from low to high, which five levels are physiological, safety, love/belonging, esteem and self-actualization [9], until Alderfer responsed to what Maslow's hierarchy of needs and amended in 1969, and advocated the ERG theory [10]. Alderfer thought the physiological and safety needs are related to survival, so should be classified as "Existence needs"; love/belonging needs are related to balancing and keeping of relationship and interpersonal, therefore has to be considered as "Relatedness needs", esteem and self-actualization needs are belong to "Growth Needs", the three demands are "ERG". Maslow advocates that human behavior motivation comes from whether their demand be satisfied. When the needs are capable of a considerable degree of satisfies, will try to pursue higher levels of demand, in this regarding, Alderfer's ERG theory also has the same opinion with it. However, the most different between Alderfer's theory and Maslow's is that ERG theory advocates: 1 . Three needs have no hierarchy, meanwhile, each needs can be achieve at the same time; 2. When fails in pursuing needs of high levels, it cause degradation and instead of lower needs satisfies, refers to, individuals pursue when they are unsatisfied with needs, different from Maslow's theory which only stay in one needs; 3 . Whatever in which level, the more difficult to complete it, the more desired to make it; 4 . After lower level needs has been satisfied, high level needs' intensity grew, on the contrary, if high levels needs lack of satisfies, lower level needs be seek for instead.

In terms of institutional long-term care service system, needs of dining and medicine of three meals and drug administrating meet the needs of basic survival. Furthermore, related to social needs, people should participate in activities and interact with people, through the process of sharing feelings and thoughts with others and link to each other, thus, all types of leisure activities and religious beliefs could be considered as a personal relationship needs. However, in long-term care system, regardless of institutional service, community service or home service emphasize the importance of rehabilitation treatment activities, then this research proposed ERGR needs, that basic concept of service design are ERG needs theory plus "Rehabilitation Needs". Using ERGR needs' structure further analysis main needs of LTCU: Dining and medication are deemed personal survival needs; all types of leisure activities and religious beliefs could be considered as a personal relationship needs; rehabilitation can be considered as personal growth needs. This research will have interview for institutional long-term care service system, collection current rehabilitation needs of LTCU, aim to user' needs and their suitable behavior field, find out behavioral model and appropriate contact 
points, then through the experience situation of contact points, find out any development available product and service. Assessing its development value and proposed improved recommends to improve life quality of LTCU.

\section{Methods}

This research uses depth interviewing and the site research, looking for participator of research, such as LTCU who currently live in senior citizens' welfare institutions or retirement center; LTCDS be focused on who currently service as full-time long-term care personnel or treatment therapist; long-term care indirect stakeholders (LTCIS) be focused on who service as long-term care institution's head or executive. There are totally three qualified senior long-term care institutions accept interview, and also physical therapist of rehabilitation department from a hospital accept interview. For current service items of long-term care, research participator who will have interview about 30 minutes to 1.5 hours, which depends on the interviewing situation at the time. Institution's executive will lead and introduce us the existing environment and equipment of long-term care institution or hospital's department. In order to completely understanding rehabilitation needs from LTCU, there is also an in-depth interviews for therapists of hospital's rehabilitation department, interview subjects focus on rehabilitation of the elder, as a course basis of LTCS rehabilitation needs of institutional services.

\section{Discussion}

\section{Interviewees Profile}

There were twelve participants in this study including one physiotherapist and one occupational therapist from the hospital; three caregivers, one senior social worker, three LTC institutional residents with rehabilitation needs, and three nurse leaders from a nursing home, an elderly housing, and a nursing institute respectively. The interviewing duration was from December 26, 2013 to August 18, 2014, and the research team came to the LTC institutions for one to four times in order to clarify real situations and experiences of every interactive touchpoints for service offerings from those LTCDSs and LTCISs to LTCU, the elderly.

\section{Rehabilitation Needs Survey and Discussion}

Rehabilitation processes of the institutional LTC service were rehabilitation assessment, rehabilitation planning, rehabilitation preparation, rehabilitation execution, and rehabilitation outcome. All those processes including the logical ordering, environment, motivation, LTCS experiences and touchpoints respectively were shown as customer journey map as Fig. 1.

1. Rehabilitation assessment. When the elderly moved into the LTC institution, the staff consisted of nurse leader, registered nurse, therapist and so on of the LTC institution made a comprehensive assessment for the elderly regarding their activities or instrumental activities of daily living. Three LTC institutions had their own full-time or contracted physiotherapist except for occupational therapist by cost consideration. The physiotherapist would have an inclusive understanding according to medical history, family history, medical history, and medication status fell records, and observed appearance of physical at present, such as chronic diseases, physical disability, paralysis degree of gait, motions reach, and balance test. Some physical state of the elderly could 
not directly distinguish from the appearance, like muscle or joint activity, etc., so they needed to do some examinations. The staff asked the elderly few tests to perform the specified actions. In the meantime, the staff took palpation, manual muscle test, range of motion test, joint range of motion, and pain test. The staff in understanding the physical condition of the elderly, it would also consult the wishes of the elderly and their families to enhance self-care ability of elderly people.

2. Rehabilitation planning. According to assess rehabilitation needs for the elderly, therapists also suggested the assessment, production, purchasing or rent for the assistive technology application for their rehabilitation exercise or activities of daily living including design and production of splints, selection of assistive and orthotics equipment, self-care device, daily live device, supporting device, and functional recovery aid training equipment.

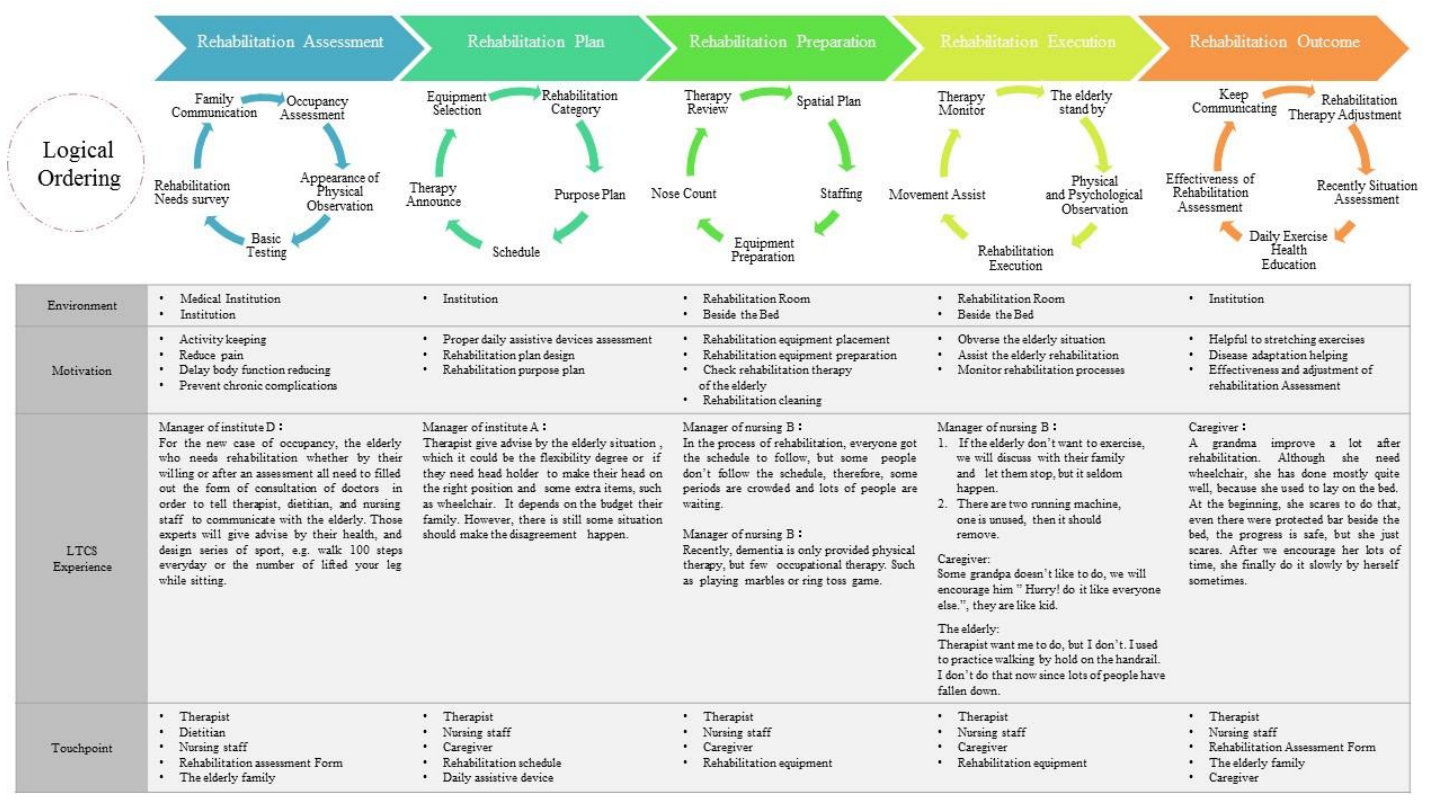

Fig. 1: Correlation between new product development and innovation

Therapists provided proper rehabilitation program to the elderly after the basic rehabilitation assessment, and the major therapies were physical therapy, occupational therapy and sport therapy. As for swallowing, bowel and bladder function training were depended on mental and physical status of the elderly assessed by nursing staff. Though three LTC institutions had physiotherapist only either hired or by contracted, however, there were still several occupational therapy equipments like reciprocal sanding, standing table, bicycle, hand rack, shoulder wheel, climbing rack, and pedal exercisers for physical function training and treatments.

3. Rehabilitation preparation. Since rehabilitation programs were offered by the physiotherapist, all assistive and equipments would be settled done, and the elderly could use them regularly. There were removable and built-in parts of assistive and equipment, and they could be divided into three types by different operating: sitting, lying down, and standing.

4. Rehabilitation execution. The elderly performed regular rehabilitation therapy in the rehabilitation room on schedule. Physical therapies were muscular endurance training, modality therapy, manual therapy, center of gravity training, balance training, and coordination training. Occupational therapies were learning and activities of daily living trainings by assistive. Sport therapies were relaxation sport, extension sport, 
breathing sport, gait sport, and neuromuscular joint sport. Every item of therapies was lasting for fifteen or twenty minutes, and a treatment per time was around two or three items. Besides being given training in the rehabilitation room, the elderly might only need to do extension sport, walking, leg elevation, or climbing in the stairwell for leg muscular training. Some of the elderly could not get out of bed and they needed caregivers' assistance.

5. Rehabilitation outcome. The therapists would adjust the treatment as proper as assistance, test and massage according to the mental and physical status of the elderly. They also gave advice about easily self-training of daily living for the elderly. The purposes of rehabilitation were maintaining motions, delaying the effects of deterioration of chronic illness or disease adaptation. However, the effectiveness was not visible in short time. Furthermore, the degree of participation and attendance rates were also major influences upon rehabilitation effectiveness for the elderly, especially some of the elderly were difficult to fully express by themselves so that their experiences had to be understand by attentive caregivers. General speaking, the caregiver reported to the nursing staff about the condition of the elderly, and then the nursing staff decide to consult or not to the doctor or the therapist according to the real situation. Feels of the elderly affected by activities or motions of daily living, and it caused the effectiveness of rehabilitation. Hence the staff would keep communicating with their families to encourage the elderly for rehabilitation therapies participation.

This research found out pain points of LTCS by touchpoints and LTCS experiences following the customer journey map, and then built up blueprints for rehabilitation needs of institutional long-term care as shown as Fig. 2 according to opportunity points of types of experiences improvements figuring out by pain points and tangible evidence of developable product or service design.

\begin{tabular}{|c|c|c|c|c|}
\hline Pain Point & $\begin{array}{l}\text { - The need of daily-used assistive } \\
\text { equipment depends on the budget of } \\
\text { the elderly family. The elderly need } \\
\text { head holder to make their head on } \\
\text { the right position. However, there is } \\
\text { still some situation should make the } \\
\text { disagreement happen. }\end{array}$ & $\begin{array}{l}\text { - Some people don't follow the } \\
\text { schedule, therefore, some } \\
\text { periods are crowded and lots of } \\
\text { people are waiting } \\
\text { - Recently, dementia is only } \\
\text { provided physical therapy, but } \\
\text { few occupational therapy. Such as } \\
\text { playing marbles or ring toss } \\
\text { game }\end{array}$ & $\begin{array}{l}\text { - There are two running } \\
\text { machine, one is unused, } \\
\text { then it should remove. } \\
\text { - Therapist want the } \\
\text { elderly to do exercise, but } \\
\text { they don't. }\end{array}$ & $\begin{array}{l}\text { - Lots of elderly don't get } \\
\text { off their bed to do } \\
\text { exercise, they need lots of } \\
\text { encouragement }\end{array}$ \\
\hline LTCS & $\begin{array}{l}\text { - Manager of LTCIS institute } \\
\text { - LTCDS nursing staff }\end{array}$ & - LTCDS- nursing staff & $\begin{array}{l}\text { - LTCDS- nursing staff } \\
\text { - LTCU }\end{array}$ & $\begin{array}{l}\text { - LTCDS-caregiver } \\
\text { - LTCU }\end{array}$ \\
\hline $\begin{array}{l}\text { Experience } \\
\text { Change }\end{array}$ & $\begin{array}{l}\text { Product experience - cost-downed } \\
\text { daily-used assistive equipment }\end{array}$ & $\begin{array}{l}\text { - Product experience - design cost- } \\
\text { downed assistive equipment for } \\
\text { occupational therapy } \\
\text { - Service experience - change } \\
\text { schedule of individual } \\
\text { rehabilitation } \\
\text { - Service experience - set an } \\
\text { rehabilitation schedule remainder }\end{array}$ & $\begin{array}{l}\text { - Space-modify } \\
\text { rehabilitation room } \\
\text { - Activity-combine } \\
\text { rehabilitation with } \\
\text { entertainment }\end{array}$ & $\begin{array}{l}\text { - Activity-awards for } \\
\text { participation } \\
\text { - Activity-awards for } \\
\text { improvement }\end{array}$ \\
\hline $\begin{array}{l}\text { Intangible } \\
\text { Proof }\end{array}$ & - Daily-used assistive equipment & $\begin{array}{l}\text { - Assistive equipment for } \\
\text { occupational therapy } \\
\text { - Rehabilitation schedule } \\
\text { - Rehabilitation room set color plan } \\
\text { - Music bell for rehabilitation }\end{array}$ & $\begin{array}{l}\text { - Relaxing rehabilitation } \\
\text { room } \\
\text { - Rehabilitation with } \\
\text { entertainment }\end{array}$ & $\begin{array}{l}\text { - Participation awards } \\
\text { - Improvement awards } \\
\text { - Happy meal awards }\end{array}$ \\
\hline
\end{tabular}

Fig. 2: Blueprints for Rehabilitation Needs of Institutional Long-Term Care Service

For execution stage of rehabilitation process, the motivation was observing the mental and physical status for the elderly before therapists assisted them to do rehabilitation, and therapists should monitor or conduct the elderly during their rehabilitation. As for LTCS experiences, nurse leader B claimed that they would try to communicate with the resident's family if he or she did not want to do rehabilitation. A 
foreign caregiver said that the elderly was like children. If they disliked doing so, she would try to cheer them up and encourage them. A resident said that the therapist asked him to do rehabilitation, but he didn't do it after that. He used to walk along with the wall leaning on handrail in the public area, but he worried about doing this thereafter because of falling down by bumping into other people especially there were lots of people there occasionally. Those LTCS experiences revealed the circumstance and pain points of space and activity. Therefore, designers could arrange multiple improving plans for space and activity experiences. For example, a totally experience improvement plan could be designed by a stress reliefs and nostalgia rehabilitation room from original space optimization of the rehabilitation room and then was combined with rehabilitation treatments of entertainment.

Furthermore, service design indicators (SDIs) for rehabilitation needs of institutional long-term care service were listed as Fig. 3 as the result of this study. The construction of SDIs was synthesized from essential point described by every LTCS during their service offering process that could meet long-term care stakeholders' needs and be a reference of intangible evidence for the LTCU experiences improvement design.

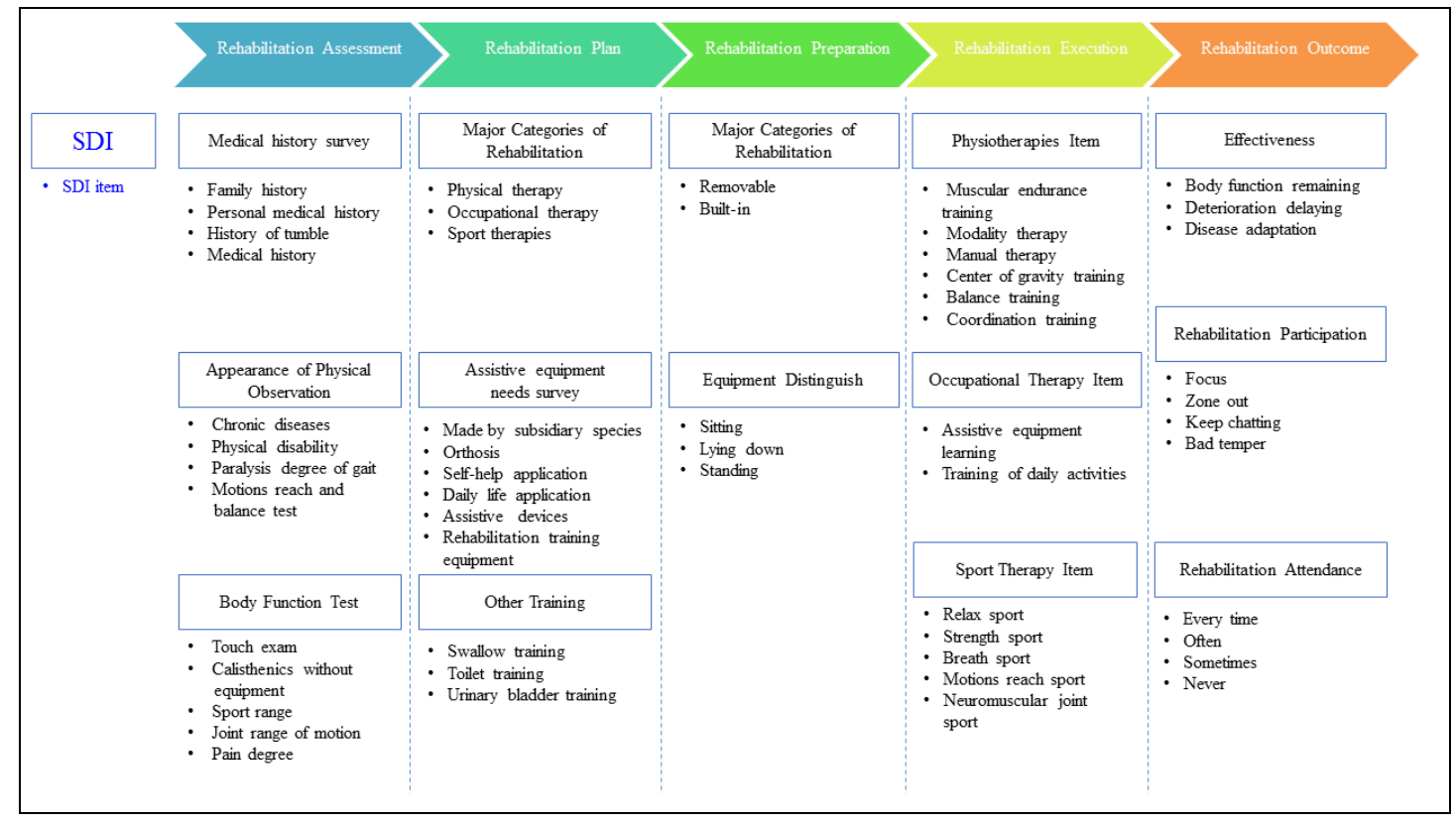

Fig. 3: Blueprints for rehabilitation needs of institutional long-term care service

According to the above analysis of the results, there are fourteen main SDIs for rehabilitation needs of institutional long-term care service including patient history investigation, the appearance of a state investigation, physical condition previewing and testing, major categories of rehabilitation, assistive needs assessment, further rehabilitation training, rehabilitation equipment placement, areas for rehabilitation equipments, physical therapy items, occupational therapy items, sport therapy items, the effectiveness of rehabilitation, rehabilitation participation and attendance rates of rehabilitation. A totally experience improvement plan should work out or adjusted by SDIs as reference, and be modified by real situation of the LTCU and the LTCDS.

\section{Conclusions}

In this study, a qualitative study was conducted to investigate the status of institutional rehabilitation services provided under existing long-term care system. From the perspective of different stakeholders, the LTCU's lifestyle and status of living could be 
understood. To summarize assessable indicators from each research prospective, and acquisition of LTCU needs and LTCS experiences via institutions visiting and in-depth interview, there were three customer experiences differing from general consumer market comparing with consumers.

1. The real customer experience was from emotional experiences constructed by the LTCU and LTCS simultaneously. When LTCU had shown their problems by language or non-language expression, that meant they needed help. LTCDS did reactions to LTCU by including understanding, thinking, and feeling. LTCDS said or did while they helped LTCU can be naturally occurring or deliberate derived [11]. The elderly lived in LTC institutions and conservation agencies looked after the elderly for 24-hour, so the elderly could direct contact and interactive with caregivers and nursing staff instead of their families. As concentration of user-centered for service design, it should be considered not only LTCU viewpoints but also LTCS experiences so that a really good experience improvement plan could be constructed when it was implemented in the long-term care system. When LTCDS experiences got improvement, they could provide better service for LTCU.

2. Customer expectations came from holistic consideration. The relationship among touchpoints, pain points and opportunity points could be found by customer journey map. Touchpoints were not entirely being problems, pain points were experiences and feelings of LTCS from their service offering for the elderly. In addition, pain points could be figured out by service design rules, and the key of opportunity points were how to convert those problems into intangible evidence by experience improvement. The long-term care system needed much holistic consideration to figure out a feasible design solution to fulfill expectations for the elderly and the stakeholders.

3. Service Design for the long-term care system was focused on experience improvement instantly. LTCS would continuously think and rethink during the design process, in other words, intangible evidence design between SDIs and LTCS experiences which were not entirely based on the relationship of cause and effect. Even the designed products and service conducted first and then modified by SDIs or referred SDIs items before products and service design, which is still performed the extent of satisfaction survey afterwards.

There are two suggestions for following research: 1. To get total LTCS prospective of other long-term care institutions in the central, southern, or eastern of Taiwan. 2. To develop different prospective SDIs by focusing on dedicated discussion for experience improvement planning with spaces and LTCS needs of activities of daily living for the elderly such as bathing, showering, dressing, functional mobility, going to the restroom, personal hygiene and grooming, and self-feeding in order to improve LTCS life quality.

\section{Acknowledgement}

Authors gratefully acknowledge the financial support for this research provided by part of the Ministry of Science and Technology under Grants No. 102-2410-H-130-064 and No. 103-2410-H-130-051.

\section{References}

[1] National Development Council, Taiwan's Population Projections from 2014 to 2061.Taipei: National Development Council, 2014. 
[2] M. R. Li, A Comparison of Long-Term Care Insurance Regulations in Taiwan and in the United States - A Case Study of Long-Term Care Insurance. Master's thesis, Feng Chia University, Taichung, 2012.

[3] K. Yang, J. Huang, Service Design Tools and Methods. Taipei: Taiwan Design Center, 2011.

[4] M. Stefan, Service Design: Practical Access to an Evolving Field. Mater dissertation, Köln International School of Design, Germany, 2005.

[5] R. M. Saco, A. P. Goncalves, Service Design-An Appraisal. Design Management Review 19(1) (2008) 10-19.

[6] B. Mager, T. J. Sung, Special issue editorial: Designing for services. International Journal of Design 5(2) (2011) 1-3.

[7] R. A. Kane, R. L. Kane, Long-term care: Principles, programs, and policies. New York: Springer, 1987.

[8] W. I. Lin, Taiwan's long-term care planning system: Retrospect and Prospect, Training course of Taiwan Association for Promoting Public Health, 2010.

[9] A. H. Maslow, A theory of human motivation. Psychological Review 50 (1943) 370-396.

[10]C. P. Alderfer, An empirical test of a new theory of human needs. Organizational Behavior and Human Performance 4(2) (1969) 142-175.

[11] Y. L. Du, Nursing and Practice. Taipei: Farseeing Publishing Group, 1999. 